\title{
Diagnoses of building thermal characteristics by parameter identification and manual inspection
}

\author{
Tatsuya Ohira ${ }^{1}$, Tatsuo Nagai ${ }^{1}$ \\ ${ }^{1}$ Tokyo University of Science, Tokyo, Japan
}

\begin{abstract}
This study proposes a method of specifying where there is leeway for improvement of thermal performance of an office building by identifying the thermal performance parameters, which refers to such as the insulation and fraction of solar shading, based on operating data. This can contribute to the planning of energy reduction retrofit. The proposed method combines two methods: identifying parameters using a thermal load calculation program and conducting an inspection following a prepared diagnosis flow. Various parameters within the input data in the thermal load calculation program are classified into a small number of group, and the representative parameters of each group are identified based on measured thermal load and room temperature. The identified and standard parameters are compared and, judging from the differences between them, it is determined whether or not each of the specified parameters is in an abnormal state. Afterwards, a diagnosis flow is proposed to specify which individual unknown parameters cause the abnormality.
\end{abstract}

\section{Introduction}

When the quantity of energy used in a completed building is larger than predicted during the design period, it must be determined whether there are areas where energy could be reduced, for instance, in the building envelope, in room usage, and in equipment and machinery.

Many research studies in Tobias Maile, Vladimir Bazjanac, and Martin Fischer (2012) and E.H.Borgstein, R.Lamberts, and J.L.M.Hensen (2016), whose titles include the word "commissioning", have been conducted to improve operation of equipment and machinery. However, there have been few research studies have considered the building envelope or the room usage. In the field of research for residential buildings, many studies in Okuyama Hiroyasu and Onishi Yoshinori (2012) and M.J.Jiménez, H.Madsen, and K.K.Andersen (2008) have conducted to identify the insulation performance. However, their studies conducted case studies in small-size buildings where nobody was living.

The objective of this study is to propose a method for estimating the thermal performance such as insulation and infiltration of occupied office buildings using actual operating data. This method is expected to be contributed to do energy-saving action for practical situations.

Figure 1 shows the proposed methodology. To establish the methodology, energy simulation is firstly conducted to identify unknown building parameters such as thermal insulation thickness and ceiling height using a thermal load calculation program.

The unknown parameters are classified into two groups which are representatives of the considerable parameters. The proposed method identifies two parameters of the groups to briefly approximate thermal performance.

Secondary, a diagnosis flow is proposed to specify which individual unknown parameters cause the abnormality in a representative.

In this study, we use virtual measurement data generated by the thermal load calculation program. The virtual measurement data was generated under the condition that some specific parameters - amount of outside air, infiltration rate, and fraction of solar shading - had abnormal values comparing to standard values. The identification result shows the possibility of detecting abnormalities in parameters.

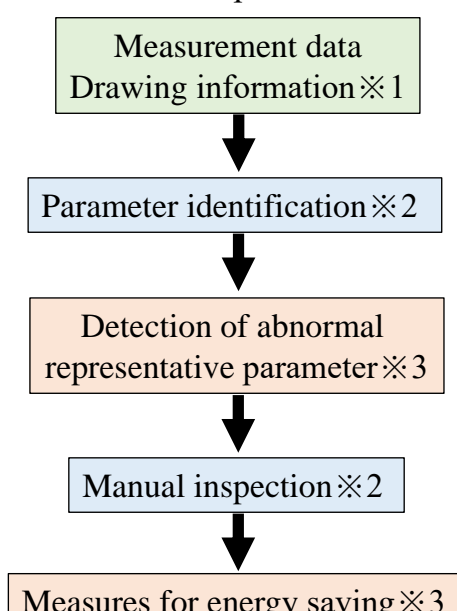

$$
\begin{aligned}
& ※ 1 \text { : Input information } \\
& ※ 2 \text { : Method } \\
& ※ 3 \text { : Output result }
\end{aligned}
$$

Figure 1: Proposed methodology for thermal performance diagnosis

\section{Outline of parameter identification and diagnosis flow}

Figure 2 shows an overview of proposed parameter identification. There are the two groups which are mentioned in Introduction section: 1) the overall conductance group (Group 1) which represents some related parameters such as the amount of outside air and infiltration rate, 2) the steady thermal load group (Group 2) which represents some parameters such as a fraction of solar shading. What is called at the beginning "representative parameter" is instead a calibration dimensionless index, which is used in equation 1) to vary all the physical properties of a group with the same 
percentage respect to their standard deviation (data in table 1).

The two representative parameters were varied in units of 0.2 from -2 to +2 . Parameter values were calculated using equation (1). When the value of a representative parameter is zero, all individual parameters which are included in each group have their mean values.

When the value of a representative parameter is +1 , it is represented by adding a standard deviation of the individual parameters to their mean values. Table 1 shows prior information (mean value and standard deviation) of each parameter. Here, this prior is used to Bayesian estimation. Air change rate, solar absorptance (outer wall) and occupant density are based on beta distribution, not normal distribution. Refer to the Appendix for details of Bayesian estimation and beta distribution.

Parameter $=$ mean $+($ standard deviation $\times$ representative parameter)

Table 1: Prior distribution (mean and standard deviation) for each parameter

\begin{tabular}{|c|c|c|}
\hline parameters & Mean & $\begin{array}{l}\text { Standard } \\
\text { deviation }\end{array}$ \\
\hline \multicolumn{3}{|l|}{ Group 1 (Overall conductance) } \\
\hline Thermal insulation thickness (outer wall)(mm) & 25 & 12 \\
\hline Thermal insulation thickness (roof)(mm) & 50 & 25 \\
\hline Amount of outside air $\left(\mathrm{m}^{3} / \mathrm{m}^{2} \mathrm{~h}\right)$ & 5 & 2 \\
\hline Ceiling height $(\mathrm{mm})$ & 2700 & 100 \\
\hline Floor height $(\mathrm{mm})$ & 3800 & 150 \\
\hline Adjacent room temperature difference factor (-) & 0.3 & 0.15 \\
\hline Thermal transmission coefficient (window) $\left(\mathrm{W} / \mathrm{m}^{2} \mathrm{~K}\right)$ & 2.9 & 1 \\
\hline air change rate $(1 / \mathrm{h})$ & 0.1 & 0.1 \\
\hline \multicolumn{3}{|l|}{ Group 2 (Steady the rmal load) } \\
\hline Ground reflectance $(\%)$ & 10 & 5 \\
\hline Height of adjacent buildings (by direction) (m) & 3 & 2 \\
\hline Depth of eaves (by direction) (m) & 0.2 & 0.1 \\
\hline Solar absorptance (outer wall) (-) & 0.8 & 0.1 \\
\hline Fraction of solar shading (Windows)(-) & 0.515 & 0.2 \\
\hline Window height $(\mathrm{mm})$ & 1900 & 200 \\
\hline Lighting electrical capacity $\left(\mathrm{W} / \mathrm{m}^{2}\right)$ & 12 & 4 \\
\hline Occupant density (people/m²) & 0.1 & 0.1 \\
\hline Electrical plug load $\left(\mathrm{W} / \mathrm{m}^{2}\right)$ & 12 & 6 \\
\hline
\end{tabular}

shown in Figure 3. The vertical and horizontal axes represent the daily thermal load and daily mean outdoor temperature, respectively.

Overall conductance mainly affects gradient of regression lines both of cooling and heating loads. Steady thermal load mainly affects the intercept of $\mathrm{x}$ axis. These two groups are chosen as principal characteristics of building thermal load.

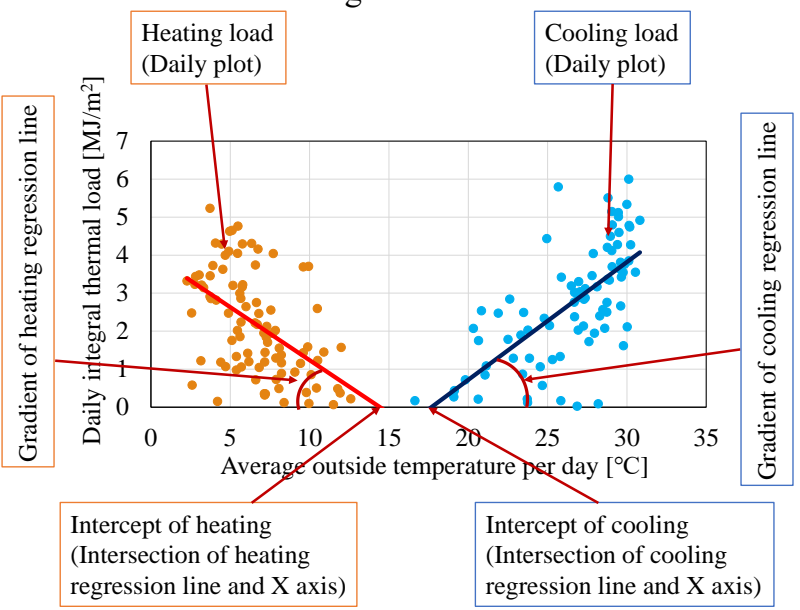

Figure 3: Explanation of scatter diagram

The two representative parameters are fitted so that the calculated thermal load and measured thermal load conform. For example, Figure 2 shows that the overall conductance (Group 1) is high because the value of the parameters after fitting is greater than $+\sigma$.

The fitting of simulated load against the "measured" load (in your experiment virtual measured load) is done modifying what I called the calibration dimensionless indexes, which in turn modify all physical properties of each group. Then you know the attributed value to all of them during the fitting procedure; of course you do not know the "true" value. Thus the "fitted" individual properties are known, while the "true" are of course not known.

\section{Thermal insulation thickness \\ Adjacent room temperature difference factor Thermal transmission coefficient (window) \\ Fraction of solar shading \\ Ground reflectance \\ Height of adjacent buildings (by direction) \\ Depth of eaves \\ air change rate \\ Amount of outside air \\ Occupant density \\ Lighting electrical capacity \\ Electrical plug load

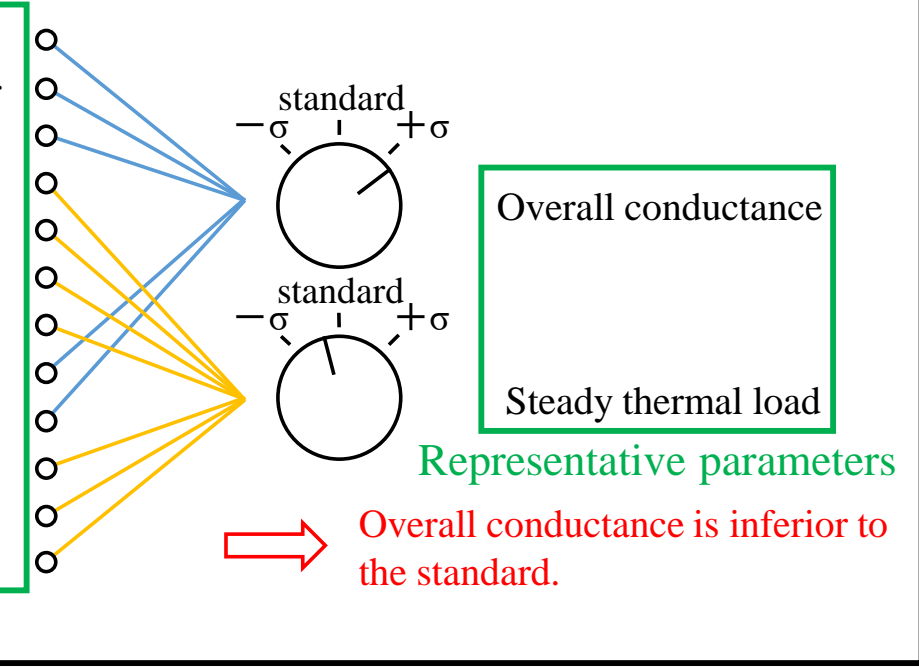 \\ Individual parameters}

Figure 2: Overview of parameter identification

The representative parameters in Table 1 were determined in terms of parameters' characteristics as
After the fitting procedure is concluded, an on-site 
investigation conducted with manual inspection is trying to select among all physical properties in that reference group, which exhibits the highest variance, those with the furthest value from a possible "true" value coming out from inspection. Hence, a diagnosis flow as shown in Figure 4 is used. This diagnosis flow is an example of a case in which identifying parameters indicated the overall conductance as being too low.

In this process, firstly the specification of windows should be investigated. When the windows performance are high, thermal insulation thickness is investigated. After that, ceiling height, and state of the adjoining rooms were investigated. Investigation completed I to IV indicates the causal factors that have been identified.

The investigation process mentioned above can determine specific parameters efficiently which should be considered to reduce energy consumption.

The specified parameters will be used to improve energy performance in the future retrofit.

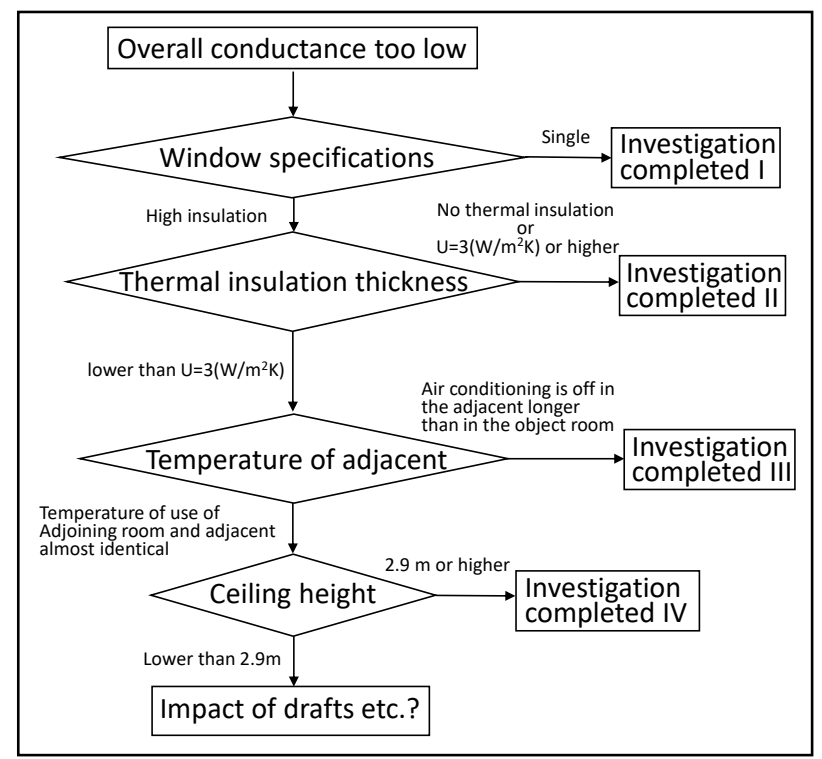

Figure 4: Example a diagnosis flow

(Assuming the case where the overall conductance is identified too low)

\section{Building conditions and calculation cases}

This study used a thermal load calculation program to compute the virtual thermal load of the building model, shown in Figure 5. Unknown parameters are identified by using these virtual data, instead of using measured data obtained from an actual building. An office building constructed in Tokyo was simulated in the program. It is a medium-height building with a total floor area of $610 \mathrm{~m}^{2}$. For outdoor air conditions, data from the Meteorological Agency for 2016 were used. The summer measurement period was from July 1 to July 31, 2016, and the winter measurement period was from January 1 to January 31 , 2016. To improve the precision of the identification of parameters, data from both periods were used. To confirm that it is possible to detect abnormalities in the parameters of a building, one parameter was selected from a number of individual parameters to prepare virtual measurement data. The value of this parameter was greatly altered from the standard value, while other values were standard. This study prepared virtual measured data for three cases by selecting the amount of outside air and infiltration rate from Group 1, and the fraction of solar shading from Group 2. Table 2 shows the parameter values, changed to prepare virtual measured data. Values of -2 and +2 were used for the representative parameter to yield the individual parameters according to equation (1).

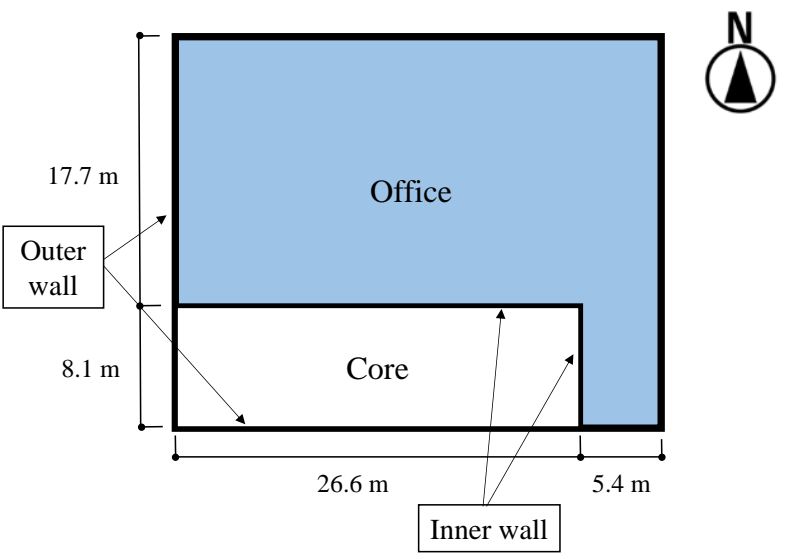

Figure 5: Plan drawing of standard building model

In calculation case (1), the amount of outside air was set to $1 \mathrm{~m} 3 / \mathrm{m} 2 \mathrm{~h}$, and individual parameters such as thermal insulation thickness, ceiling height and floor height of same group as the amount of outside air were set to their mean values.

Table 2: Parameter settings for generating virtual measurement data

\begin{tabular}{|l|c|c|}
\hline$(1)$ & \multirow{2}{*}{$\begin{array}{c}\text { Amount of } \\
\text { outside air }\end{array}$} & $1 \mathrm{~m}^{3} / \mathrm{m}^{2} \mathrm{~h}$ \\
\cline { 1 - 2 } & & $9 \mathrm{~m}^{3} / \mathrm{m}^{2} \mathrm{~h}$ \\
\hline (3) & \multirow{3}{*}{ air change rate } & $0.011 / \mathrm{h}$ \\
\cline { 1 - 1 } & & $0.2751 / \mathrm{h}$ \\
\hline (5) & fraction of & 0.115 \\
\cline { 1 - 1 } (6) & solar shading & 0.915 \\
\hline
\end{tabular}

\section{Results of identifying parameters}

Table 3 shows the values of the parameters in each group calculated by parameter identification. In calculation case (1) whose amount of outside air is $1 \mathrm{~m}^{3} / \mathrm{m}^{2} \mathrm{~h}$, the representative parameter 1 is identified as -2 , and the representative parameter is identified as 0.2 . The values written in Italics show the groups to which the changed parameters belong. The amount of outside air and infiltration rate are presented in Group 1, and the fraction of solar shading is given in Group 2. The values of the parameters written in italics shows that the changes from zero in the infiltration rate and the fraction of solar shading did not reach 1 , revealing that these cannot be significantly detected. In addition, the symbols of the values of the measured and the identified parameters did not coincide. However, the amount of outside air could be detected when it was $1 \mathrm{~m}^{3} / \mathrm{m}^{2} \mathrm{~h}$. Parameters belonging to the group not written in Italics were fixed at zero, and the virtual measured data were prepared, but the identified parameters were calculated as values that diverged from zero. 
Table 3: Results of identified representative parameters

\begin{tabular}{|c|c|c|c|}
\hline \multicolumn{2}{|c|}{} & \multicolumn{2}{c|}{$\begin{array}{c}\text { representative } \\
\text { parameters }\end{array}$} \\
\cline { 3 - 4 } \multicolumn{2}{|c|}{} & group1 & group2 \\
\hline \multirow{3}{*}{ Amount of outside air } & $1 \mathrm{~m}^{3} / \mathrm{m}^{2} \mathrm{~h}$ & $\mathbf{- 2}$ & 0.2 \\
\cline { 2 - 4 } & $9 \mathrm{~m}^{3} / \mathrm{m}^{2} \mathrm{~h}$ & $\mathbf{0 . 6}$ & 0.6 \\
\hline \multirow{2}{*}{ air change rate } & $0.011 / \mathrm{h}$ & $\mathbf{- 0 . 8}$ & 0.4 \\
\cline { 2 - 4 } & $0.2751 / \mathrm{h}$ & $\mathbf{- 0 . 4}$ & 0.4 \\
\hline fraction of & 0.115 & -0.6 & $\mathbf{0 . 2}$ \\
\cline { 2 - 4 } solar shading & 0.915 & -0.6 & $\mathbf{0 . 6}$ \\
\hline
\end{tabular}

※group1: Overall conductance group2: Steady thermal load

Figure 6 and 7 show the results of sensitivity analysis of thermal load. The representative parameter values of -2 and +2 are used to calculate each individual parameter value, setting the other individual parameters to 0 . The changes in thermal load for the change in each individual parameter are shown in figure 6 and 7 . The positive sign means the increase in thermal load compared to that calculated by setting all individual parameters to 0 . The loads were calculated for summer (July) and winter (January). The figures show that the amount of outside air has a big impact on the monthly thermal load both in summer and winter. In contrast, infiltration rate and the fraction of solar shading have relatively small impact. If this is considered along with the results shown in Table 3, there is close relationship between the possibility of the detection in a parameter abnormality and the sensitivity of the parameter on thermal load.

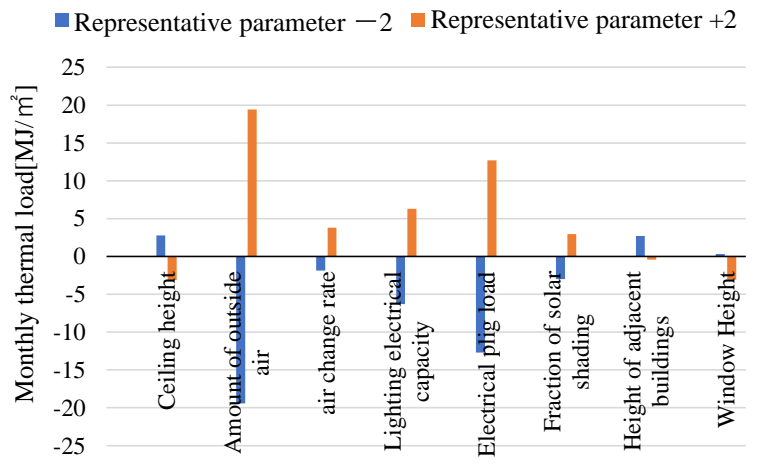

Figure 6: Sensitivity analysis of each unknown parameter in summer (July)

Representative parameter $-2 \quad$ Representative parameter +2

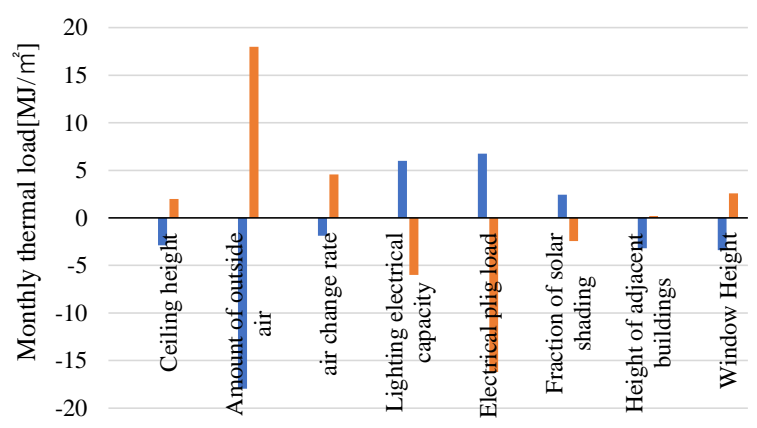

Figure 7: Sensitivity analysis of each unknown parameter in winter (January)
Figures 8 are regression line derived from each case shown in Table 2. The solid lines are the regression lines based on virtual measurement data generated with the values shown in Table2. The dotted lines are the regression lines obtained from the simulation results in which the representative parameters are set to the identified value shown in Table 3. As shown in Table 3, the signs of the identified parameters did not coincide with those of the actual parameters. One reason for this is the fact that in all cases (Figures 8), the gradient of the identified regression line was smaller, and the intercepts were changed towards lower temperature compared to those derived from the virtual measurement. These biases might hinder the accurate reproduction of the regression line.

\section{Improving precision by the correction method using gradient and intercept}

Table 4 shows the results before and after parameter corrections. The detail of the correction method is noted in Appendix. In the parameter corrections, the identified parameter values were changed to approach the gradient and intercept values of the regression lines obtained from the virtual measurement. The signs of the corrected parameters (in Italics) coincide to those of actual parameters. This result indicates that appropriate correction makes the precision of abnormality detection higher for the amount of outside air. On the other hand, the absolute values of identified representative parameters for infiltration rate and the fraction of solar shading are not greater than 1, thus the abnormality detections are difficult. This result shows that it is possible to detect the abnormality in a parameter only when the parameter has a big impact on thermal load.

Table 4: Result of identified representative parameter before and after corection

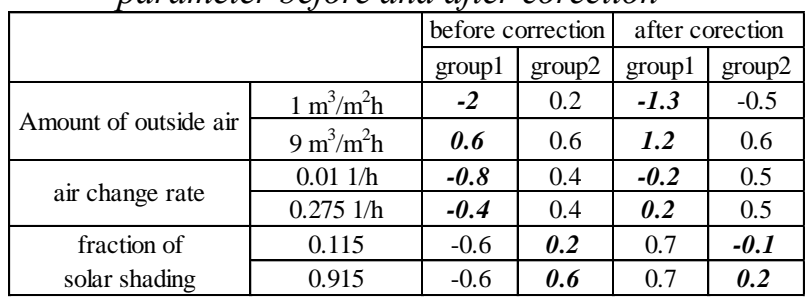




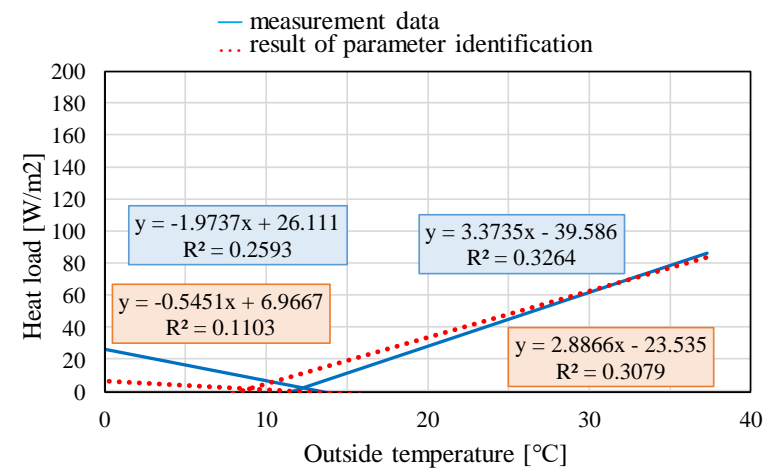

(1) Amount of outside air: $1 \mathrm{~m}^{3} / \mathrm{m}^{2} \mathrm{~h}$

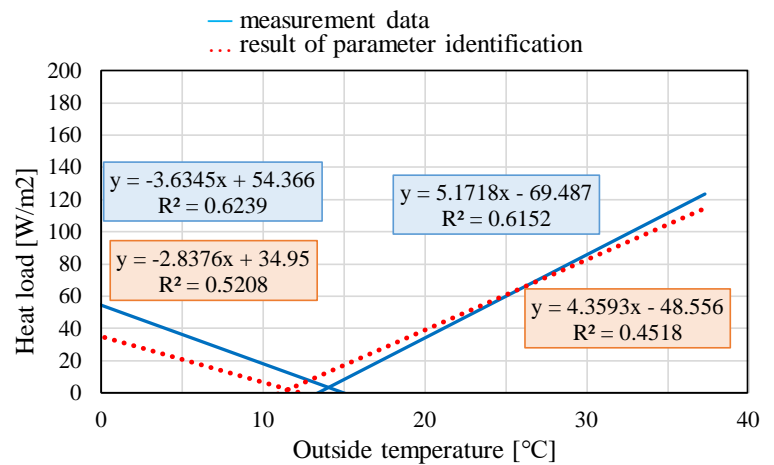

(3) air change rate : $0.011 / \mathrm{h}$

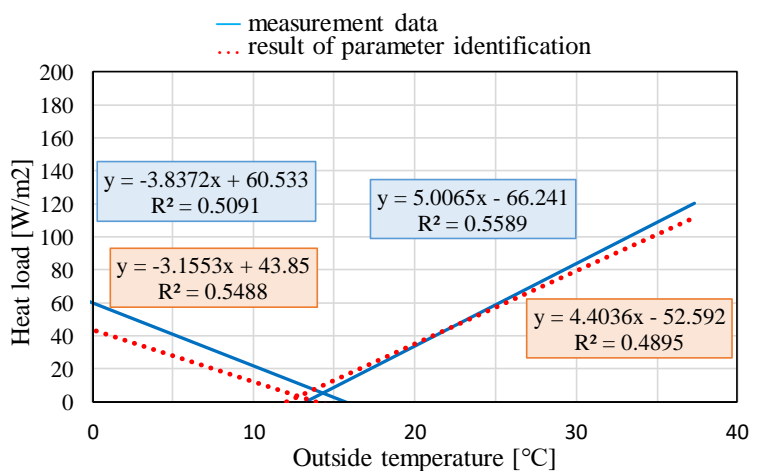

(5) fraction of solar shading : 0.115

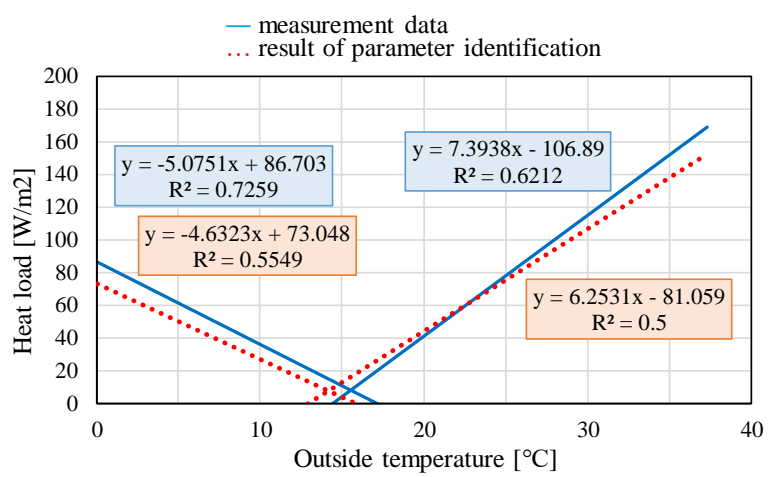

(2) Amount of outside air: $9 \mathrm{~m}^{3} / \mathrm{m}^{2} \mathrm{~h}$

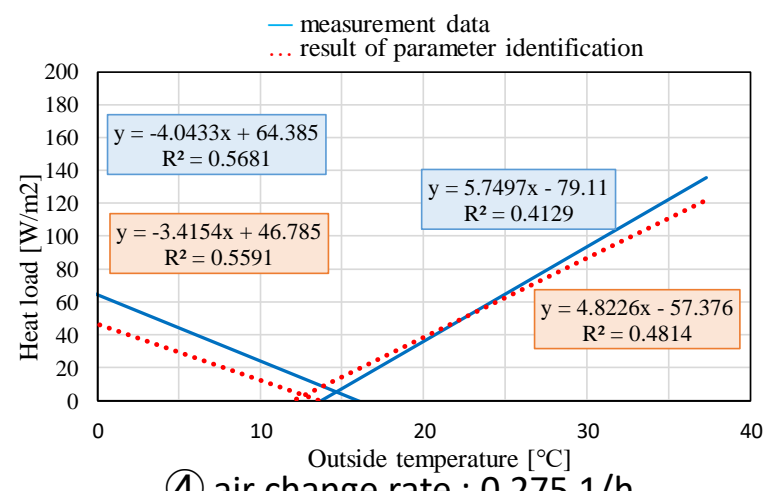

(4) air change rate : $0.2751 / \mathrm{h}$

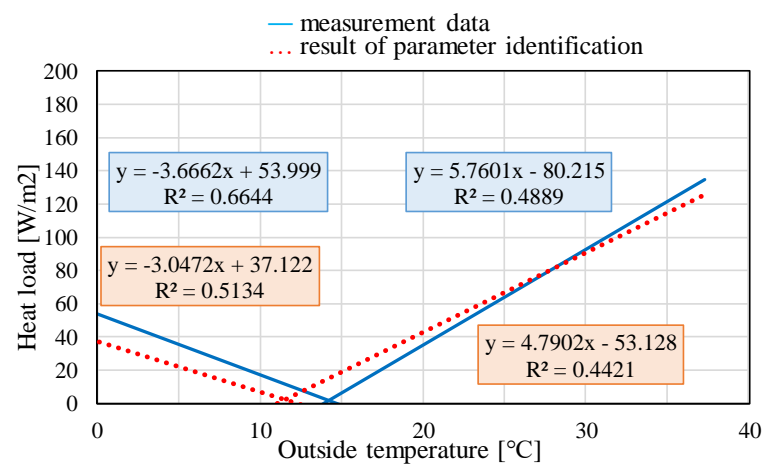

(6) fraction of solar shading : 0.915

Figure 8: Comparison of regression line of virtual measurement data and calculation result

\section{Conclusion}

Clarifying a building's thermal characteristics at the operating stage plays a vital role in energy-saving. The objective of this study is to propose a method for estimating the thermal performance such as insulation and infiltration of occupied office buildings using actual operating data. This method is expected to be contributed to energy-saving during operating stage.

In this study, the possibilities of detecting abnormality in thermal performance parameters are studied, using virtual thermal load generated by thermal load calculation program. The unknown parameters are classified into two groups which are representatives of the considerable parameters. The proposed method identifies two parameters of the groups to briefly approximate thermal performance.
The result show that it is possible to detect the abnormality in a parameter with a big impact on thermal load such as the amount of outside air. In addition, appropriate correction makes the detection precision higher.

In the future, it is better to change the fitting target from the thermal load to the gradient and intercept of the regression line. In addition, it will be necessary to use actual measurement data instead of virtual measurement. Establishing an inspection procedure following a prepared diagnosis flow is also needed.

\section{References}

1) Tobias Maile, Vladimir Bazjanac, and Martin Fischer (2012). A method to compare simulated and measured data to assess building energy performance. Building and Environment, pp 241-251 
2) E.H.Borgstein, R.Lamberts, and J.L.M.Hensen (2016). Evaluating energy performance in non-domestic buildings. A review, Energy and Buildings, pp734-755

3) Okuyama Hiroyasu and Onishi Yoshinori (2012). System parameter identification theory and uncertainty analysis methods for apendixmulti-zone building heat transfer and infiltration. Building and Environment, pp 39-52

4) M.J.Jiménez, H.Madsen, and K.K.Andersen (2008). Identification of the main thermal characteristics of building components using MATLAB. Building and Environment, pp 170-180

5) Tatsuya Ushiyama, Tatsuo Nagai, SumioShiochi, and Hiroyuki Murayama (2014). Annual Thermal Load Estimation Using Prior Information and Short-term Measurement Data. ASim 2014

\section{Appendix}

\section{Bayesian estimation}

Bayesian estimation is used by Ushiyama (2014).

The probability density was updated with Bayesian estimation when new information was obtained. The Bayesian estimation is represented in equation (2).

Posterior probability $\propto$ Likelihood $\times$ Prior probability

The procedures to combine the representative parameters of group 1 and 2 are described below.

Step 1): The prior probability, $\mathrm{f}(\mathrm{x})_{\mathrm{w}}$, was calculated with equation (3). Prior distribution of the representative parameters of group 1 and 2 was calculated with equation (4).

$$
\mathrm{f}(\mathrm{x})_{\mathrm{w}}=\mathrm{f}(\mathrm{x})_{1} \times \mathrm{f}(\mathrm{x})_{2}
$$

$\mathrm{f}(\mathrm{x})_{1}$ :Prior distribution of representative parameter of group 1

$\mathrm{f}(\mathrm{x})_{2}$ : Prior distribution of representative parameter of group 2

$$
f(x)=\frac{1}{\sqrt{2 \pi \sigma}} \exp ^{-\frac{(x-\mu)^{2}}{2 \sigma^{2}}}
$$

$$
\begin{aligned}
& \sigma^{2}: \text { Variance }(=1) \\
& \mathrm{x} \text { : Representative parameter value } \\
& \mu \text { : Mean of representative parameter }(=0)
\end{aligned}
$$

Step 2):The parameter value was calculated with equation (1). The zone air temperature and sensible heat load during the measurement period were calculated using the heat load calculation program.
Step 3): The likelihood, $\mathrm{L}(\mathrm{x})_{\mathrm{w}}$, was calculated with equation (5).L(x) and $\mathrm{L}(\mathrm{x})_{2}$ were calculated with equation (6).

$$
\mathrm{L}(\mathrm{x})_{\mathrm{w}}=\prod_{i} \mathrm{~L}(\mathrm{x})_{1} \times \prod_{i} \mathrm{~L}(\mathrm{x})_{2}
$$

$\mathrm{L}(\mathrm{x})_{1}$ : Likelihood of representative parameters, $\mathrm{x}$ for average zone air temperature during unconditioned period for each day

$\mathrm{L}(\mathrm{x})_{2}$ : Likelihood of representative parameters, $x$ for daily sensible heat load

i: Day index

$$
L(x)=\frac{1}{\sqrt{2 \pi \sigma}} \exp ^{-\frac{(g(x)-\mu)^{2}}{2 \sigma^{2}}}
$$

$\sigma^{2}$. Variance

$\mu$ : Average room temperature during unconditioned period and integrated daily heat load (Actual measurement)

$\mathrm{g}(\mathrm{x})$ : Average room temperature during unconditioned period and integrated daily heat load (Simulation)

Step 4): The posterior probability was calculated by multiplying the likelihood with the prior probability.

\section{Beta distribution}

The range of the distribution function is not an infinite value, and any value (finite value) can be set. Also, the graph is distorted to the right or left depending on the values of $\mathrm{p}$ and $\mathrm{q}$.

Probability density function

$$
f(x)=k(x-a)^{p-1}(b-x)^{q-1}
$$

\section{$\mathrm{k}$ : constant}

a : lower limit

b : upper limit

$\mathrm{a} \leqq \mathrm{x} \leqq \mathrm{b} \quad, \quad 0<\mathrm{p} \quad, \quad 0<\mathrm{q}$

mean : $\mathrm{a}+\frac{p}{p+q}(b-a)$

standard debiation : $\frac{p q}{(p+q)^{2}(p+q+1)}(b-a)$

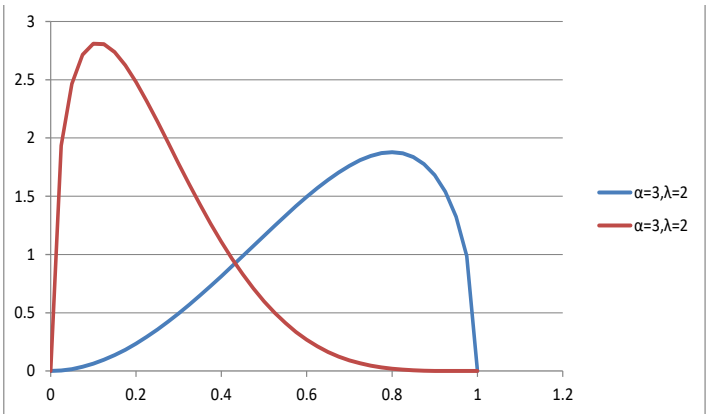

Figure 9: Image of beta distribution 


\section{Method of correction using information about gradients and intercepts}

This correction method uses the information of the gradient and intercept of the value of the parameter.

[1] The value of the representative parameter from -2 to 2 such as overall conductance and steady thermal load is changed. Based on the above parameters, virtual measurement data in the actual measurement period of summer and winter is calculated. The change amount (representative parameter is -2 to +2 ) of the gradient and intercept of the regression line obtained from the data is calculated. The values obtained in Tables 5 and 6 are shown.

Table 5: Quantity of change by gradients $※$

\begin{tabular}{|l|r|r|}
\hline & Heating & \multicolumn{1}{l|}{ Cooling } \\
\hline Overall conductance & $\mathbf{5 . 7 1}$ & $\mathbf{4 . 8 9}$ \\
\hline Steady thermal load & 1.33 & 4.7 \\
\hline
\end{tabular}

Table 6: Quantity of change by intercepts $※$

\begin{tabular}{|l|r|r|}
\hline & \multicolumn{1}{|c|}{ Heating } & \multicolumn{1}{|c|}{ Cooling } \\
\hline Overall conductance & $\mathbf{8 . 2 3}$ & $\mathbf{8 . 5 4}$ \\
\hline Steady thermal load & 12.51 & 7.28 \\
\hline
\end{tabular}

[2] The difference of the gradients and intercepts obtained when the result of the parameter identification is subtracted from the virtual measurement data in Figures 8 are calculated. The values obtained in Tables 7 and 8 are shown.

Table 7: Quantity of change by gradients ※

\begin{tabular}{|c|c|r|r|}
\hline \multicolumn{2}{|c|}{} & Heating & Cooling \\
\hline \multirow{2}{*}{$\begin{array}{c}\text { Amount of outside } \\
\text { air }\end{array}$} & $\mathbf{1 ~ \mathrm { m } ^ { 3 } / \mathrm { m } ^ { 2 } \mathrm { h }}$ & $\mathbf{1 . 4 2}$ & $\mathbf{0 . 4 8}$ \\
\cline { 2 - 4 } & $\mathbf{9 \mathrm { m } ^ { 3 } / \mathrm { m } ^ { 2 } \mathrm { h }}$ & $\mathbf{0 . 4 5}$ & $\mathbf{1 . 1 4}$ \\
\hline \multirow{2}{*}{ air change rate } & $\mathbf{0 . 0 1 1 / h}$ & $\mathbf{0 . 7 9}$ & $\mathbf{0 . 8 1}$ \\
\cline { 2 - 4 } & $\mathbf{0 . 2 7 5} \mathbf{1 / h}$ & $\mathbf{0 . 6 2}$ & $\mathbf{0 . 9 3}$ \\
\hline fraction of \\
solar shading & 0.115 & 0.68 & 0.61 \\
\cline { 2 - 4 } & 0.915 & 0.62 & 0.97 \\
\hline
\end{tabular}

Table 8: Quantity of change by intercepts ※

\begin{tabular}{|c|c|c|c|}
\hline & & Heating & Cooling \\
\hline \multirow{2}{*}{$\begin{array}{c}\text { Amount of outside } \\
\text { air }\end{array}$} & $1 m^{3} / m^{2} h$ & 0.45 & 3.58 \\
\hline & $9 m^{3} / m^{2} h$ & 1.31 & 1.5 \\
\hline \multirow{2}{*}{ air change rate } & $0.011 / h$ & 2.64 & 2.3 \\
\hline & $0.2751 / h$ & 2.22 & 1.86 \\
\hline \multirow{2}{*}{$\begin{array}{c}\text { fraction of } \\
\text { solar shading }\end{array}$} & 0.115 & 0.3 & 1.29 \\
\hline & 0.915 & 2.55 & 2.83 \\
\hline
\end{tabular}

[3] The value corrected of parameter are calculated using Figure 10, the value obtained in [1], and the value obtained in [2].

$※$ The values written in Italics are Group 1, and the rest are Group 2.
$\mathrm{X}_{1}=4 \times \mathrm{B} / \mathrm{A}$

$\mathrm{X}_{2}=4 \times \mathrm{B} / \mathrm{A}$

$\mathrm{X}=\left(\mathrm{X}_{1}+\mathrm{X}_{2}\right) / 2$

$\mathrm{X}$ : Value corrected based on cooling and heating

$\mathrm{X}_{1}$ : Value corrected based on cooling

$\mathrm{X}_{2}$ : Value corrected based on heating

A : Difference of gradient and intercept when the value of a representative parameter is changed from -2 to 2 . (Table 5,6)

B : Difference values of gradient and intercept of measured and identified parameters. (Table 7,8)

Figure 10: Calculation methods 